\title{
Definindo melhores práticas em projetos de Regeneração Urbana Sustentável
}

\author{
Defining best practices in Sustainable Urban Regeneration \\ projects
}

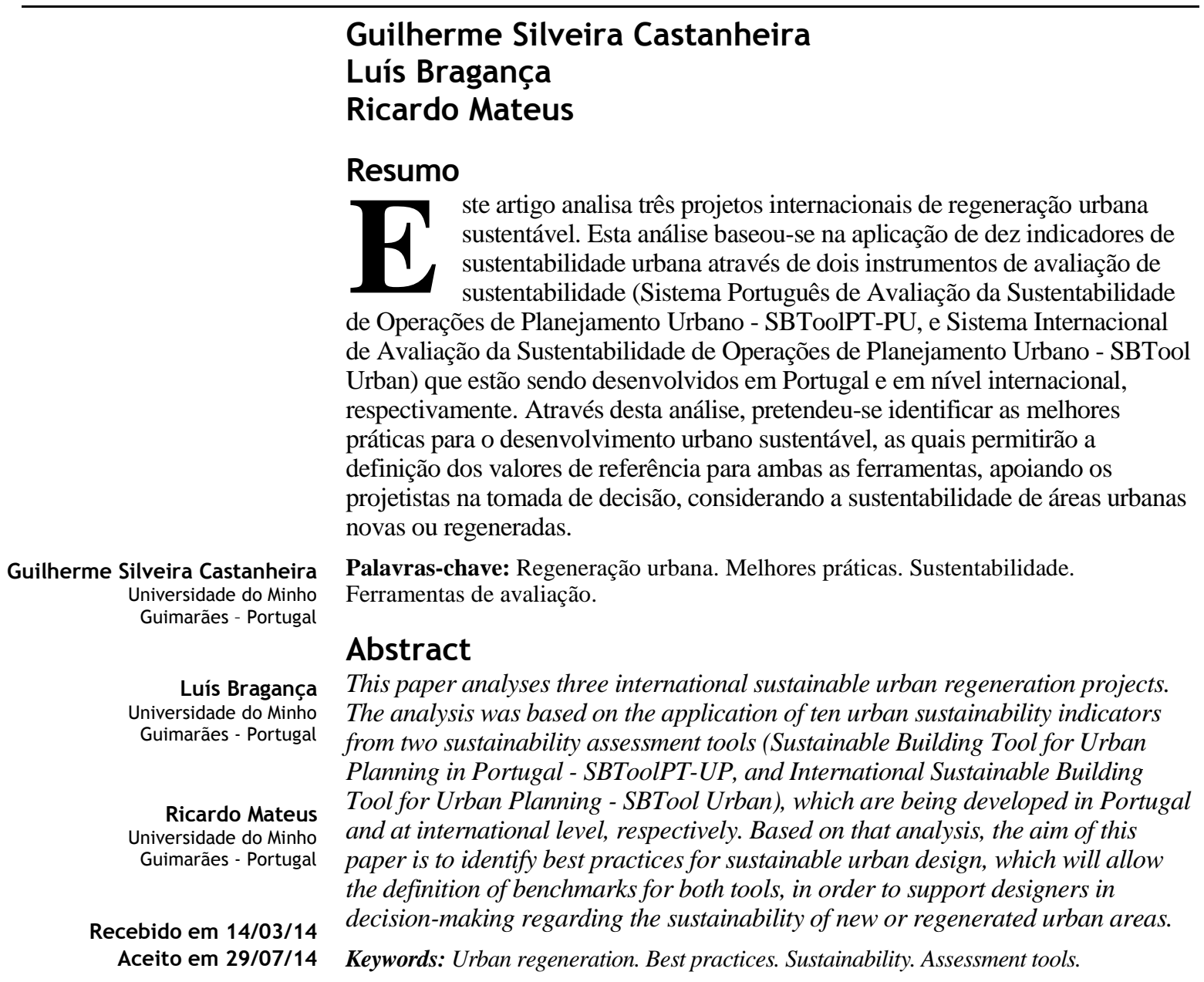




\section{Introdução}

A regeneração urbana está na agenda de muitas cidades, questão que tem adquirido importância cada vez maior. Aspectos como aumentar a satisfação dos cidadãos, recentemente, constituem a base de muitos projetos urbanos (novos ou de regeneração). Neste momento, o objetivo não é apenas preservar o patrimônio cultural, mas também evitar a expansão urbana descontrolada, evitar o uso excessivo de recursos naturais e melhorar a qualidade de vida da população. Sabese que, em conjunto, os edifícios e as outras obras da construção civil consomem mais de $50 \%$ dos recursos naturais globais utilizados a cada ano (PACHECO-TORGAL; JALALI, 2012; MATEUS; BRAGANÇA, 2011) e que estudos atuais preveem que até 2050 quase $70 \%$ da população mundial estará vivendo em cidades (UNITED..., 2012). Esses dados resumem as preocupações mundiais e deixam evidências de que a regeneração urbana é considerada um dos mecanismos fundamentais para a concretização do desenvolvimento urbano sustentável (TURCU, 2012). Souza e Awad (2012) argumentam que o desenvolvimento sustentável se apresenta mais urgentemente onde residem os problemas $\mathrm{e}$ acreditam que as cidades darão as respostas para um futuro sustentável, uma vez que elas são as maiores consumidoras de recursos e as maiores geradoras de resíduos do planeta.

Recentemente, alguns projetos de regeneração urbana chamam a atenção por sua maior preocupação com a sustentabilidade, assim como com seu legado. De acordo com Dale e Newman (2009), a regeneração urbana tem sido vista como uma ferramenta para criar "zonas de incubação" para o desenvolvimento sustentável, e sua aplicação tem sido expressa em alguns projetos com pensamentos de longo prazo, direcionados ao benefício do cidadão e da cidade, com influência direta, principalmente, na área de atuação do projeto, isto é, o local de intervenção. Esses tipos de projeto, apoiados em princípios de sustentabilidade, são responsáveis pelo desenvolvimento e pela disseminação de estratégias e políticas urbanas de regeneração das cidades e/ou de zonas urbanas. Adicionalmente, esses projetos permitem demonstrar, na prática, a viabilidade e os benefícios resultantes da integração de princípios de sustentabilidade nas cidades.

No entanto, tem havido pouca investigação no que diz respeito a benchmarking (valores de referência - melhores práticas e práticas convencionais -, com os quais se compara o desempenho) na regeneração urbana, devido principalmente à relativa juventude da regeneração urbana sustentável (SALAT; LABBÉ; NOWACKI, 2011). Mesmo sabendo que os projetos de regeneração urbana sustentável, como instrumentos de políticas públicas, auxiliam a promoção das cidades (MENDES, 2013), é importante definir, para além das boas intenções, quais são as melhores práticas sustentáveis e os melhores benchmarks quantitativos/qualitativos, que sirvam de suporte a planejadores urbanos para a obtenção de melhores resultados em seus projetos. Já existem alguns fóruns para troca de experiências entre cidades, mas é preciso ressaltar que não existem soluções únicas, uma vez que cada local e cada projeto necessitam de medidas específicas relacionadas a suas características próprias (MIANA, 2010).

A Europa é o continente com maior experiência em regeneração urbana, com destaque ao Reino Unido, Alemanha e França (COUCH; SYKES; BÖRSTINGHAUS, 2011). Assim, com o intuito de aprimorar o desenvolvimento da ferramenta para avaliação da sustentabilidade do ambiente construído (SBTool ${ }^{\mathrm{PT}}$-PU), este estudo analisou três projetos europeus de regeneração urbana:
(a) Parque das Nações, Lisboa (Portugal);
(b) La Confluence, Lyon (França); e
(c) Parque Olímpico Rainha Elizabeth, Londres (Inglaterra).

Primeiramente foi escolhido um projeto que estivesse inserido dentro do território de Portugal (Lisboa) e outros dois projetos que representassem a experiência dos países destacados (Inglaterra e França). Embora o projeto do Parque das Nações seja o mais antigo (1993-2007), ele representa um dos melhores exemplos de regeneração urbana em âmbito internacional, sendo a primeira e mais reconhecida experiência portuguesa de gestão do território (PARQUE..., 2014), bem como a de maior escala. Já os projetos de Lyon e Londres representam a atualidade dos projetos de regeneração urbana europeus e as últimas tendências em estratégias urbanas.

Com objetivos e propostas diferenciados, esses três projetos são importantes para a definição das melhores práticas, que auxiliarão o desenvolvimento da ferramenta SBTool $^{\text {PT }}$-PU e SBTool Urban, bem como o aprimoramento dos métodos de avaliação.

Os estudos de caso escolhidos têm características comuns, basearam-se na reabilitação de antigas áreas industriais que foram abandonadas ou degradadas, e são considerados, pelas entidades que realizam investigação no domínio das cidades

8 Castanheira, G. S.; Bragança, L.; Mateus, R. 
sustentáveis, como projetos de referência em termos do potencial contributo das operações de regeneração urbana para a sustentabilidade do ambiente construído. Projetos de regeneração urbana estão ligados, geralmente, a espaços devolutos e/ou zonas industriais abandonadas considerados vazios urbanos -, e seu princípio está na tentativa de resolver os problemas urbanos dessas áreas por meio de melhorias econômicas, sociais, ambientais e físicas (ROBERTS; SYKES, 2000), como a reutilização de edificações desocupadas e a melhoria das infraestruturas, dos equipamentos e dos serviços urbanos.

Através da análise desses projetos, foi possível verificar como as estratégias de regeneração urbana estão sendo aplicadas pelas autoridades na busca de cidades mais sustentáveis, de melhoria da qualidade de vida de seus cidadãos, com respeito ao meio ambiente e a seus recursos naturais.

\section{Como medir as melhores práticas?}

O objetivo deste estudo é definir as melhores práticas atuais em relação ao que é feito em Portugal e em outros projetos europeus de regeneração urbana. $\mathrm{O}$ processo de definição das melhores práticas baseou-se no uso de indicadores de sustentabilidade, uma vez que são instrumentos fundamentais para a análise urbana, desenho de políticas, estratégias, ações e programas de desenvolvimento urbano sustentável (ROSALES, 2011). Os indicadores são a base para medir a sustentabilidade, no entanto é preciso ter muito cuidado na escolha dos indicadores a serem utilizados em cada contexto, porque aqueles selecionados para medir a sustentabilidade de uma área urbana podem não ser aplicáveis a outras.

Os indicadores considerados neste estudo são baseados no trabalho realizado no desenvolvimento da metodologia SBTool $^{\text {PT }}$ (sistema português para a avaliação da sustentabilidade do ambiente construído) para planejamento urbano (SBTool ${ }^{\mathrm{PT}}$-PU). Essa ferramenta ainda está sendo desenvolvida e seguirá os passos da metodologia global, que considera um conjunto de indicadores relacionados a diferentes categorias e avaliados por um conjunto de parâmetros. Esses indicadores, juntamente com suas categorias, representam as três dimensões do desenvolvimento sustentável: ambiental, social e econômica. Com o lançamento da primeira versão, no final de 2013, essa ferramenta permite a avaliação da sustentabilidade de projetos de planejamento urbano e de regeneração urbana, mas também serve como um guia para a aplicação das melhores práticas, auxiliando o desenvolvimento de cidades mais sustentáveis.

A estrutura dessa metodologia está sendo desenvolvida e adaptada ao contexto português pelo Laboratório de Física e Tecnologia das Construções da Universidade do Minho, com base no trabalho de Serge Salat (SALAT; LABBÉ; NOWACKI, 2011) e nos trabalhos desenvolvidos pela Iniciativa Internacional para a Sustentabilidade do Ambiente Construído (iiSBE) e pelo grupo de trabalho do SBTool Urban (INTERNATIONAL..., 2014), que também está em desenvolvimento. Um esforço cooperativo está sendo realizado para a melhoria dessas metodologias tendo em conta os últimos desenvolvimentos científicos em sustentabilidade na escala urbana.

$\mathrm{O}$ processo de desenvolvimento de indicadores da metodologia SBTool $^{\mathrm{PT}}$-PU foi fundamentado no seguinte objetivo: criar uma lista de indicadores que fosse organizada, transparente, objetiva e que levasse em consideração os aspectos mais importantes do desenvolvimento sustentável. Essa lista foi desenvolvida com base no atual estado da arte das metodologias que avaliam a sustentabilidade de projetos urbanos e comunidades urbanas, e com base nos indicadores da ferramenta de avaliação da sustentabilidade de edifícios SBTool $^{\mathrm{PT}}$. O estado da arte considerou três das principais ferramentas de avaliação da sustentabilidade de projetos de planejamento urbano e comunidades (HAAPIO, 2012): CASBEE-UD (Comprehensive Assessment System for Building Environmental Efficiency for Urban Development) (COMPREHENSIVE..., 2007), BREEAM Communities (Building Research Establishment Environmental Assessment Method for Communities) (BUILDING..., 2009) e LEEDND (Leadership in Energy and Environmental Design for Neighborhood Development) (LEADERSHIP..., 2009). Além destas, outras três metodologias também foram consideradas: EarthCraft Communities (EARTH..., 2013), Green Star Communities (GREEN..., 2014) e One Planet Living (BIOREGIONAL, 2014).

De acordo com Bragança et al. (2013), a ferramenta SBTool ${ }^{\mathrm{PT}}$-PU abrange doze categorias sob o escopo das principais dimensões da sustentabilidade (ambiental, social e econômica). Além disso, uma categoria extra é considerada, abrangendo a sustentabilidade de edifícios e as tecnologias de informação e comunicação. Os 41 indicadores incluídos nessa ferramenta, bem como as respectivas categorias e dimensões, são apresentados na Tabela 1. A metodologia apresenta ainda, para cada indicador, o processo de avaliação, os valores adotados para cada critério e 
os valores correspondentes à melhor prática (percentuais que devem ser definidos como metas nos projetos sustentáveis).

\section{Estudos de caso}

\section{Projeto Parque das Nações (1993-2007)}

Localizado na zona oriental de Lisboa, o Parque das Nações (Figuras 1 e 2 ) é um projeto ambicioso, que surgiu com a candidatura da cidade para organizar a última Exposição Mundial do século XX, a EXPO'98, com o objetivo de regenerar uma degradada zona portuária industrial.
A antiga área industrial, que havia sido abandonada, estava totalmente obsoleta, apresentando problemas de contaminação do solo devido aos metais pesados e petróleo, mas que detinha, no entanto, grande potencial de desenvolvimento devido a sua proximidade com o rio Tejo. O projeto consistiu na regeneração urbana e ambiental de uma área de 340 ha (PARQUE..., 2014), modernização e internacionalização de Lisboa, reestruturação e reabilitação, bem como a instalação de novos acessos, transportes, amenidades, serviços e infraestrutura, demonstrando grande cuidado com o tecido urbano.

Tabela 1 - Lista de categorias e indicadores de sustentabilidade da metodologia SBTool ${ }^{\mathrm{PT}}$-PU

\begin{tabular}{|c|c|c|c|}
\hline Dimensões & Categorias & ID & Indicadores de Sustentabilidade \\
\hline \multirow{21}{*}{ Ambiental } & \multirow{3}{*}{ C1. Forma Urbana } & I1 & Planejamento Solar Passivo \\
\hline & & $\mathrm{I} 2$ & Potencial de Ventilação \\
\hline & & $\mathrm{I} 3$ & Rede Urbana \\
\hline & \multirow{5}{*}{ C2. Uso do Solo e Infraestrutura } & I4 & Aptidões Naturais do Solo \\
\hline & & I5 & Densidade e Flexibilidade de Usos \\
\hline & & I6 & Reutilização de Solo Urbano \\
\hline & & $\mathrm{I} 7$ & Reabilitação do Ambiente Construído \\
\hline & & I8 & Rede de Infraestruturas Técnicas \\
\hline & \multirow{4}{*}{ C3. Ecologia e Biodiversidade } & I9 & Distribuição de Espaços Verdes \\
\hline & & $\mathrm{I} 10$ & Conectividade de Espaços Verdes \\
\hline & & I11 & Uso de Vegetação Autóctone \\
\hline & & $\mathrm{I} 12$ & Monitoramento Ambiental \\
\hline & \multirow{3}{*}{ C4. Energia } & $\mathrm{I} 13$ & Eficiência Energética \\
\hline & & $\mathrm{I} 14$ & Energias Renováveis \\
\hline & & $\mathrm{I} 15$ & Gestão Centralizada de Energia \\
\hline & \multirow{3}{*}{ C5. Água } & I16 & Consumo de Água Potável \\
\hline & & $\mathrm{I} 17$ & Gestão Centralizada de Água \\
\hline & & I18 & Gestão de Efluentes \\
\hline & \multirow{3}{*}{ C6. Materiais e Resíduos } & $\mathrm{I} 19$ & Materiais Sustentáveis \\
\hline & & $\mathrm{I} 20$ & Resíduos de Construção e Demolição \\
\hline & & $\mathrm{I} 21$ & Gestão de Resíduos Sólidos Urbanos \\
\hline \multirow{15}{*}{ Social } & \multirow{4}{*}{ C7. Conforto Exterior } & $\mathrm{I} 22$ & Qualidade do Ar \\
\hline & & $\mathrm{I} 23$ & Conforto Térmico Exterior \\
\hline & & I24 & Poluição Acústica \\
\hline & & $\mathrm{I} 25$ & Poluição Luminosa \\
\hline & \multirow{2}{*}{ C8. Segurança } & I26 & Segurança nas Ruas \\
\hline & & $\mathrm{I} 27$ & Riscos Naturais e Tecnológicos \\
\hline & \multirow{3}{*}{ C9. Amenidades } & $\mathrm{I} 28$ & Proximidade a Serviços \\
\hline & & I29 & Equipamentos de Lazer \\
\hline & & $\mathrm{I} 30$ & Produção Local de Alimentos \\
\hline & \multirow{3}{*}{ C10. Mobilidade } & $\mathrm{I} 31$ & Transporte Público \\
\hline & & $\mathrm{I} 32$ & Acessibilidade Pedestre \\
\hline & & $\mathrm{I} 33$ & Rede de Ciclovias \\
\hline & \multirow{3}{*}{ C11. Identidade Local e Cultural } & I34 & Espaços Urbanos Públicos \\
\hline & & $\mathrm{I} 35$ & Valorização do Patrimônio \\
\hline & & $\mathrm{I} 36$ & Integração e Inclusão Social \\
\hline \multirow{3}{*}{ Econômica } & \multirow{3}{*}{$\begin{array}{l}\text { C12. Emprego e } \\
\text { Desenvolvimento Econômico }\end{array}$} & $\mathrm{I} 37$ & Viabilidade Econômica \\
\hline & & $\mathrm{I} 38$ & Economia Local \\
\hline & & $\mathrm{I} 39$ & Empregabilidade \\
\hline \multirow{2}{*}{ EXTRA } & & $\mathrm{I} 40$ & Edifícios Sustentáveis \\
\hline & & I41 & Tecnologias de Informação e Comunicação \\
\hline
\end{tabular}

10 Castanheira, G. S.; Bragança, L.; Mateus, R. 
Figura 1 - Vista aérea do Parque das Nações

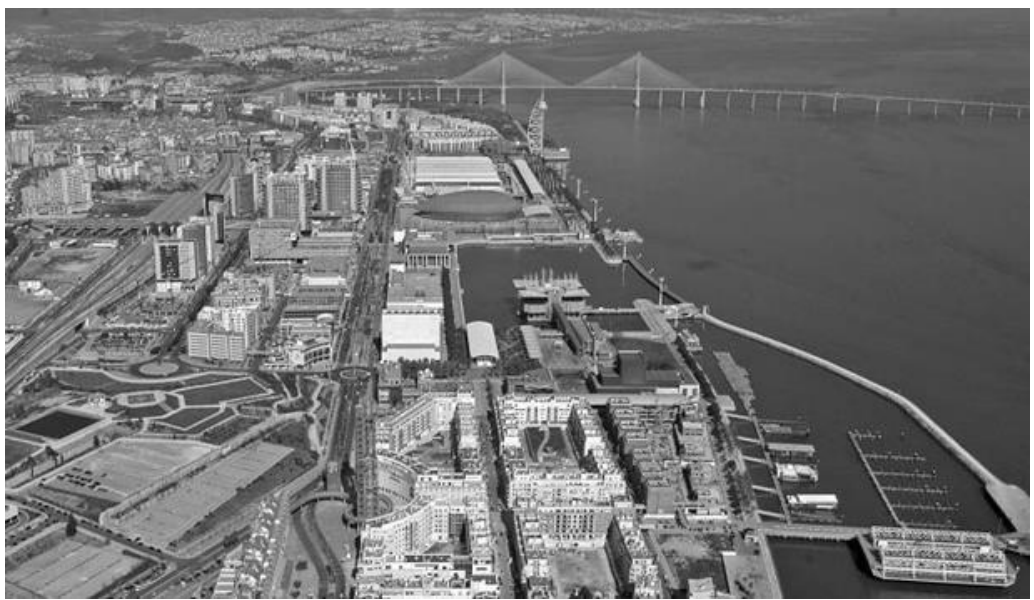

Fonte: Parque Expo (2014).

Figura 2 - Planta do Parque das Nações

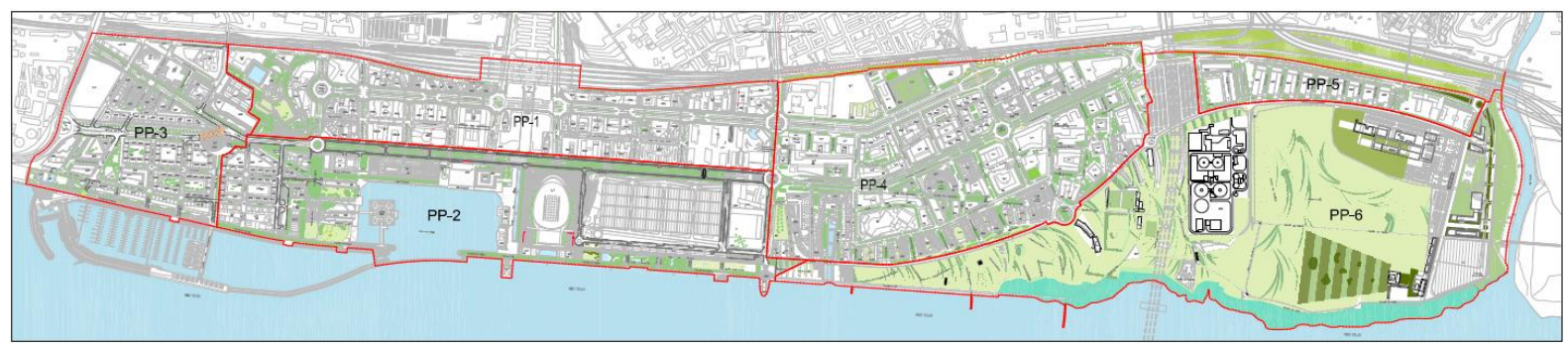

Fonte: Portal das Nações (2014).

\section{Projeto La Confluence (2003-2016)}

La Confluence (Figuras 3 e 4) consiste em uma proposta contemporânea que respeitou o legado histórico da região. Localizado no extremo sul da península central de Lyon, na confluência dos rios Rhône e Saône, é um projeto que visou à renovação de uma área de 150 ha (SPLA..., 2012), caracterizada pelo desenvolvimento de um subúrbio industrial. Entre os princípios de projeto estava a extensão do atual centro da cidade, com a criação de generosos espaços públicos, tornando o local acessível a todos os cidadãos, garantindo a mistura social, o equilíbrio de funções (habitação, escritórios, lazer, comércio) e a sustentabilidade da cidade.

\section{Projeto Parque Olímpico Rainha Elizabeth (2005-2030)}

O Parque Olímpico Rainha Elizabeth (Figuras 5 e 6) é um projeto que demonstra a experiência do Reino Unido em regeneração urbana. O parque está localizado no leste de Londres, mais precisamente em uma região conhecida como Lower Lea Valley, caracterizada por deter os bairros mais pobres da cidade. É considerada a área com a maior taxa de desemprego do Reino Unido, com baixo acesso a espaços abertos, isolada por acessos precários, o rio e terrenos abandonados - embora não estando muito distante do centro de Londres. O projeto combinou a reabilitação e descontaminação de uma área de 226 ha (LONDON..., 2012). Os autores do projeto tinham como objetivo disponibilizar uma nova infraestrutura pública que proporcionasse benefícios em longo prazo para os moradores da cidade, incluindo emprego, habitação, oportunidades educacionais e recreativas, além do desenvolvimento do esporte. 
Figura 3 - Place Nautique, vitrine do projeto

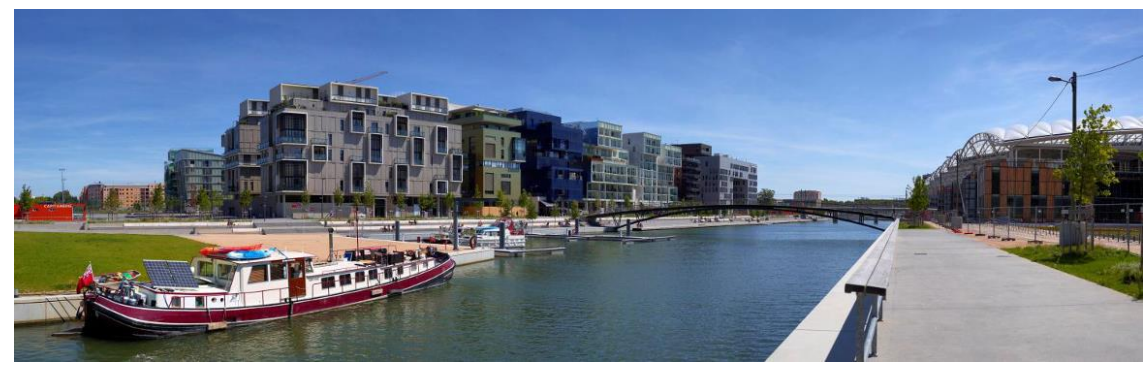

Fonte: Spla Lyon Confluence (2012).

Figura 4 - Vista aérea do projeto La Confluence

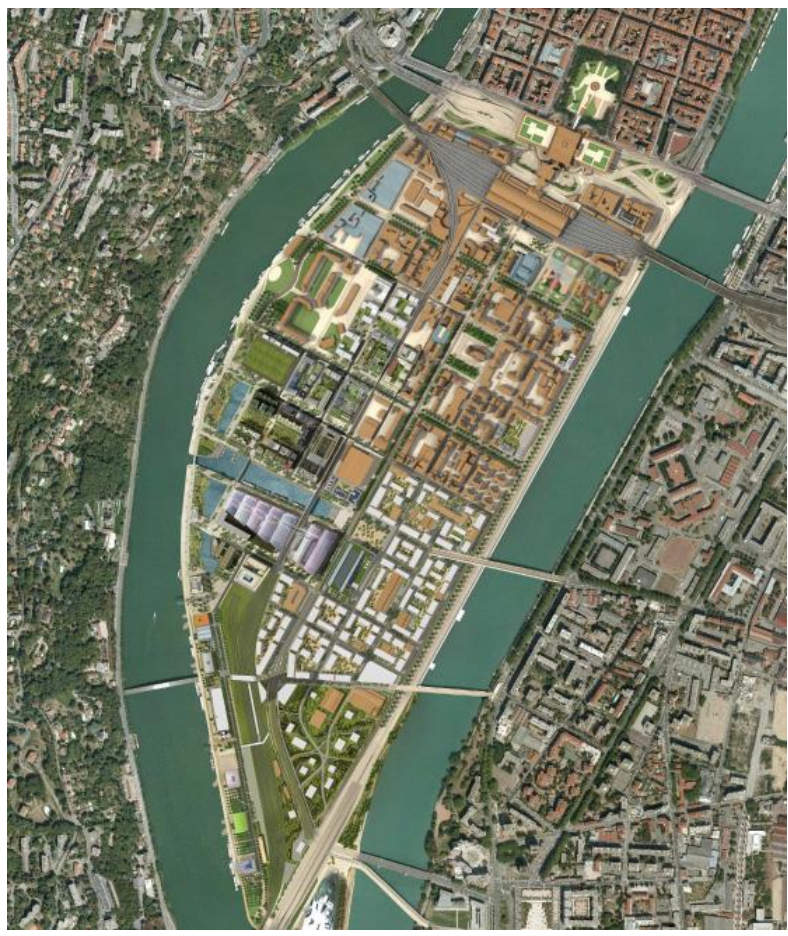

Fonte: Spla Lyon Confluence (2012).

Figura 5 - Parque Olímpico em tempos de Jogos, à esquerda, e pós-Jogos, à direita

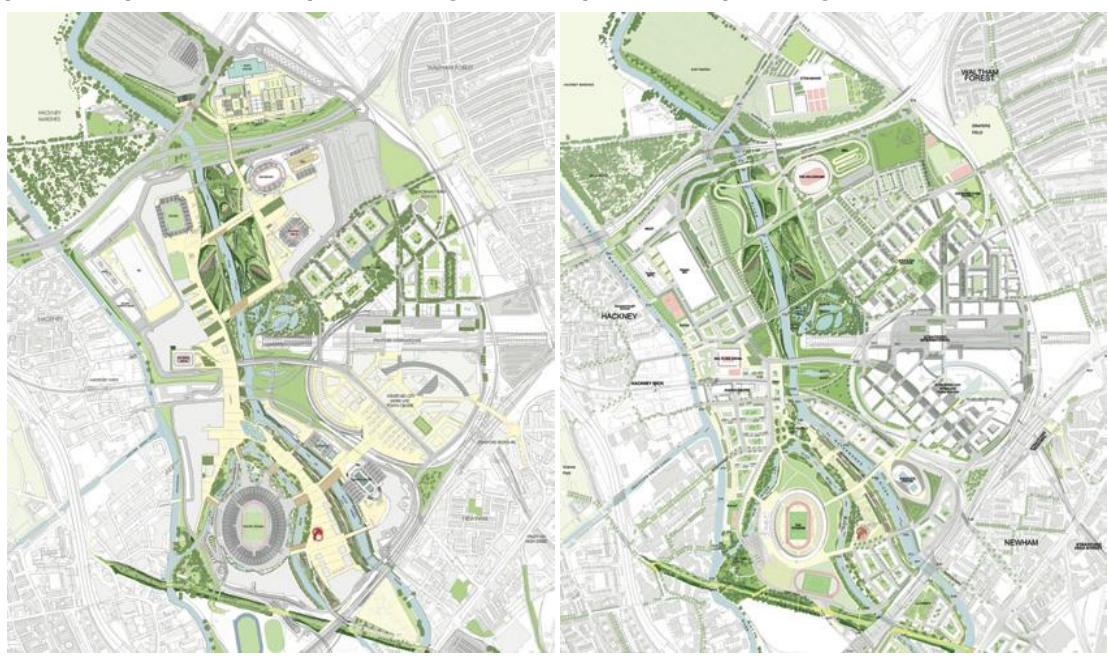

Fonte: Olympic Park Legacy Company (2012).

12 Castanheira, G. S.; Bragança, L.; Mateus, R. 
Figura 6 - Lower Lea Valley antes da regeneração e depois
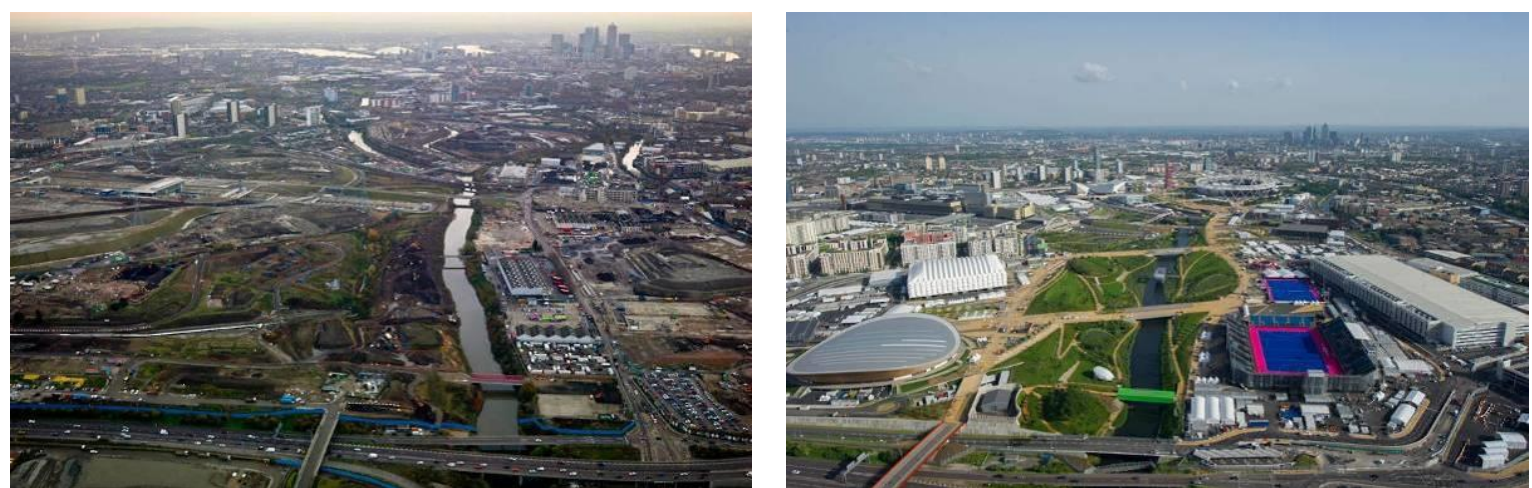

Fonte: Hawkes (2013).

\section{Resultados e análise dos resultados}

Da lista de 41 indicadores da ferramenta SBTool $^{\mathrm{PT}}$-PU, apenas 10 foram analisados: $4 \mathrm{da}$ dimensão ambiental, 5 da dimensão social e 1 da dimensão econômica. Esses 10 indicadores foram selecionados tendo por base a informação disponível, aqueles para os quais existem informações em todos os projetos. Além de garantir que os indicadores pertenciam às três dimensões do desenvolvimento sustentável, os autores tiveram o cuidado rigoroso de garantir que as características básicas dos indicadores estivessem presentes em cada estudo de caso, a fim de proporcionar condições para uma comparação adequada entre eles. Adicionalmente, salienta-se que a estrutura das metodologias de avaliação é fixa e baseada num conjunto de indicadores e parâmetros que foram considerados, por parte das entidades responsáveis por seu desenvolvimento, os mais representativos da sustentabilidade dos projetos de desenvolvimento urbano.

Dessa forma, poderá haver algumas características que foram consideradas pelas equipes de projeto, mas que não constituem mais-valia nos métodos de avaliação considerados. A lista de indicadores, os parâmetros avaliados e seus resultados, bem como os valores de melhor prática, são apresentados na Tabela 2.

Para cada indicador foi desenvolvido um ou dois métodos de avaliação. Os métodos variam entre processos quantitativos e qualitativos; os quantitativos referem-se a fórmulas matemáticas de fácil compreensão, com resultados em porcentagem; e os qualitativos são apresentados através de listas de verificação com fatores variáveis, em que, para cada item da lista, foi definido um valor, sendo o total posteriormente convertido para valores em porcentagem (entre $0 \%$ e $100 \%$ ), para melhor compreensão. Em seguida, nas próximas subseções, mais explicações sobre os indicadores utilizados e resultados obtidos são apresentados.

\section{Reutilização de solo urbano}

Este indicador promove a contenção da expansão urbana através da reutilização de áreas previamente construídas e o adequado tratamento de solos contaminados (caso se verifique). Todos os projetos apresentam a reutilização e descontaminação do solo. No entanto, em Lyon o desenvolvimento se deu, em parte, numa área existente da cidade, com habitações que preenchem praticamente metade da área total de intervenção (área em que foi realizada a reabilitação dos edifícios sem a descontaminação do solo), e a outra parcela previamente ocupada por atividades industriais. Sendo assim, sua porcentagem de descontaminação do solo é inferior a dos outros projetos, $61 \%$ de área descontaminada para os $100 \%$ de Londres e Lisboa.

O desempenho dos projetos de regeneração urbana ao nível desse indicador foi medido através da avaliação da porcentagem de solo reutilizado e descontaminado, que resulta do quociente entre o somatório das áreas em que o solo foi descontaminado e área total da zona de intervenção.

Algumas regiões não contemplam legislação específica sobre reabilitação de solos contaminados, que determine metas, como é o caso de Portugal (AGÊNCIA..., 2014). Dessa forma, o valor de melhor prática será o índice maior que 95\% de reutilização de áreas construídas e/ou com solos contaminados. Esse valor foi adotado com base nos estudos de caso analisados e em resultados dos estudos desenvolvidos por Hemphill, Berry e McGreal (2004a, 2004b), em que os autores analisam seis projetos e relatam que os de regeneração urbana sustentáveis devem 
atingir a meta de recuperação de mais de $95 \%$ da área contaminada. A metodologia BREEAM Communities (BUILDING..., 2009) defende, para este indicador, como melhor prática a reutilização de $100 \%$ de áreas previamente construídas e o reúso de áreas com solo contaminado.

\section{Reabilitação do ambiente construído}

Este indicador promove a reabilitação e a reconstrução em detrimento da construção de raiz, com o objetivo de conservar a herança de cada local e seu patrimônio edificado, através de práticas sustentáveis de reabilitação. Promove, assim, a eficiência de recursos materiais, energia e água.

No projeto de Londres não foram identificadas ações de preservação e reabilitação de construções existentes, visto não existirem construções de valor arquitetônico no terreno. Em Lisboa a situação é praticamente a mesma, somente sendo reaproveitada uma antiga torre de refinaria. No entanto, o projeto envolveu a recuperação de duas infraestruturas preexistentes, Doca dos Olivais (antiga doca) e o Aterro Sanitário de Beirolas duas infraestruturas importantes para a área. Lyon destaca-se pelo grande número de edificações de valor arquitetônico e histórico, e por ter promovido práticas sustentáveis de reabilitação, proporcionando diferentes usos mediante a adaptação às necessidades atuais.

O desempenho dos projetos de regeneração urbana ao nível desse indicador foi mensurado por meio da avaliação da porcentagem de estruturas existentes reutilizadas e reabilitadas, que resulta do quociente entre o somatório da área de construções reutilizadas e reabilitadas e o total da área construída.

Com base na análise dos casos de estudo, nos resultados dos estudos realizados por Hemphill, Berry e McGreal (2004a, 2004b) e no estado da arte das metodologias de avaliação da sustentabilidade para planejamento urbano, a melhor prática será o índice igual ou superior a $40 \%$ do total da área construída que foi reutilizada e reabilitada. A metodologia BREEAM Communities (BUILDING..., 2009) define como melhor prática a reutilização e reabilitação de mais de $50 \%$ das construções existentes, já a metodologia EarthCraft Communities (EARTH..., 2013) defende que no mínimo $30 \%$ das construções existentes devam ser reaproveitadas e reabilitadas.

Tabela 2 - Análise dos Projetos - Indicadores de sustentabilidade considerados e desempenho obtido ao nível de cada indicador de sustentabilidade

\begin{tabular}{|c|c|c|c|c|c|}
\hline $\begin{array}{c}\text { Indicadores de } \\
\text { Sustentabilidade }\end{array}$ & Parâmetros & Londres & Lisboa & Lyon & $\begin{array}{l}\text { Melhor } \\
\text { prática }\end{array}$ \\
\hline $\begin{array}{l}\text { Reutilização de Solo } \\
\text { Urbano }\end{array}$ & $\begin{array}{l}\text { Porcentagem de área de solo } \\
\text { descontaminado }\end{array}$ & $100 \%$ & $100 \%$ & $61 \%$ & $>95 \%$ \\
\hline $\begin{array}{l}\text { Reabilitação do Ambiente } \\
\text { Construído }\end{array}$ & $\begin{array}{l}\text { Porcentagem de estruturas } \\
\text { existentes reabilitadas e } \\
\text { reutilizadas }\end{array}$ & $0 \%$ & $10,15 \%$ & $44 \%$ & $\geq 40 \%$ \\
\hline $\begin{array}{l}\text { Distribuição de Espaços } \\
\text { Verdes }\end{array}$ & Porcentagem de espaços verdes & $19,91 \%$ & $32,35 \%$ & $20 \%$ & $\geq 25 \%$ \\
\hline Gestão dos Efluentes & Índice de gestão de efluentes & $57 \%$ & $50 \%$ & $57 \%$ & $\geq 57 \%$ \\
\hline Segurança nas Ruas & Índice de segurança nas ruas & $94 \%$ & $88 \%$ & $82 \%$ & $\geq 80 \%$ \\
\hline Transporte Público & $\begin{array}{l}\text { Índice de qualidade e frequência } \\
\text { dos transportes públicos }\end{array}$ & $77,33 \%$ & $76 \%$ & $82,67 \%$ & $\geq 70 \%$ \\
\hline Rede de Ciclovias & $\begin{array}{l}\text { Índice de qualidade da rede de } \\
\text { ciclovias }\end{array}$ & $87,5 \%$ & $75 \%$ & $94 \%$ & $\geq 85 \%$ \\
\hline Espaços Urbanos Públicos & $\begin{array}{l}\text { Porcentagem de espaços urbanos } \\
\text { públicos }\end{array}$ & $45 \%$ & $57 \%$ & $43 \%$ & $\geq 40 \%$ \\
\hline \multirow[t]{2}{*}{ Integração e Inclusão Social } & $\begin{array}{l}\text { Porcentagem de habitação } \\
\text { acessível }\end{array}$ & $34 \%$ & $0 \%$ & $25 \%$ & $\geq 20 \%$ \\
\hline & $\begin{array}{l}\text { Índice de participação da } \\
\text { população }\end{array}$ & $75 \%$ & $33 \%$ & $92 \%$ & $\geq 75 \%$ \\
\hline Empregabilidade & Índice de empregabilidade & $100 \%$ & $83 \%$ & $50 \%$ & $\geq 75 \%$ \\
\hline
\end{tabular}

14 Castanheira, G. S.; Bragança, L.; Mateus, R. 


\section{Distribuição de espaços verdes}

O principal objetivo deste indicador é promover a proteção e valorização da biodiversidade local. Entretanto, promovem-se também outros benefícios resultantes do uso dos espaços verdes urbanos, que incluem: melhoria da saúde física e psicológica dos habitantes; coesão social; mitigação das mudanças climáticas; redução da poluição; conservação da biodiversidade; melhoria do microclima urbano e da qualidade do ar em seu entorno; aumento das áreas permeáveis da cidade; e benefícios estéticos. Embora o projeto de Lisboa tenha a maior porcentagem de espaços verdes, esses espaços são menos uniformemente distribuídos do que nos projetos do Parque Olímpico e La Confluence.

O desempenho dos projetos de regeneração urbana ao nível deste indicador foi avaliado através da porcentagem de espaços verdes existentes na área de intervenção, ou seja, a razão do somatório de todos os espaços verdes existentes pela área total do projeto. De acordo com Singh, Pandey e Chaudhry (2010), há algumas tendências emergindo de cidades que destinam $20 \%$ a $30 \%$ da área total para seus espaços verdes urbanos. Já um estudo abrangente em 386 cidades europeias (FULLER; GASTON, 2009) sugere que atualmente a cobertura de espaços verdes varia significativamente, com média de 18,6\%. Com base nesses estudos e nos dados dos estudos de caso, definiu-se como melhor prática o valor correspondente à média do intervalo referido por Singh, Pandey e Chaudhry (2010). Assim, a melhor prática corresponde ao projeto de regeneração urbana em que $25 \%$ ou mais da área total de projeto é destinada a espaços verdes.

\section{Gestão de efluentes}

O objetivo é reduzir o uso dos sistemas de esgotos e drenos principais, introduzindo um sistema in situ para o tratamento de resíduos e de águas pluviais, permitindo sua reutilização, por exemplo, para irrigação, e ajudando a reduzir a ocorrência de inundações. Este indicador foi avaliado apenas pelo índice de gestão de efluentes (Tabela 3), através de um processo qualitativo (lista de verificação). $\mathrm{O}$ valor do índice será igual ao somatório dos pontos correspondentes a cada um dos critérios apresentados na Tabela 3 , tendo em conta que o somatório máximo é igual a 70 pontos. No final, esse resultado deverá ser convertido para porcentagem. Os critérios da Tabela 3 representam as práticas utilizadas nos projetos caso de estudo e alguns dos requisitos encontrados nas metodologias de avaliação da sustentabilidade de projetos de planejamento urbano e comunidades, mencionadas anteriormente.

Em geral, os projetos de regeneração urbana analisados apresentaram preocupações com a gestão de efluentes. Em todos os casos de estudo as águas residuais e pluviais foram tratadas, no local ou proximidades, e reaproveitadas, em sua maioria, para rega dos espaços verdes urbanos.

Portanto, a melhor prática corresponde a projetos que apresentam plano de gestão de águas de superfície, que consideram os princípios e técnicas de infiltração e percolação (para controle da erosão do solo), evapotranspiração (implantação e proteção de coberturas verdes, corredores verdes), que englobam sistemas de tratamento e reutilização de água in situ e que aplicam medidas adicionais. De acordo com a lista de verificação desenvolvida e as pontuações, a melhor prática para o índice de gestão de efluentes corresponde a valores iguais ou superiores a $57 \%$.

\section{Segurança nas ruas}

Este indicador tem como objetivo promover a segurança dos utilizadores da área urbana e a prevenção da criminalidade, através do desenho urbano. A preocupação com a segurança dos pedestres se faz presente em todos os projetos, com destaque ao Parque Olímpico, por ter utilizado como base de projeto os princípios Secured by Design ${ }^{1}$.

O desempenho dos projetos de regeneração urbana ao nível deste indicador foi medido pelo índice de segurança nas ruas, avaliado através de uma lista de verificação (Tabela 4). Esse índice será igual ao somatório dos pontos correspondentes a cada um dos critérios apresentados na Tabela 4, tendo em conta que o somatório máximo é igual a 17 pontos. Após, esse resultado deverá ser convertido para porcentagem. Os critérios a serem avaliados foram desenvolvidos tendo como exemplo os princípios Crime Prevention Through Environmental Design (CPTDE).

A melhor prática será o projeto que apresente índice de segurança nas ruas com valores iguais ou superiores a $80 \%$. O bom desempenho dos projetos de regeneração urbana baseiam-se na implementação de medidas relativas a algumas estratégias-chave: territorialidade (pensar em orientação e dimensões dos lotes, ruas e casas que incentivem a interação entre vizinhos; acentuar

\footnotetext{
${ }^{1}$ Secured by Design (SBD) é uma iniciativa emblemática da polícia do Reino Unido que reforça os princípios Crime Prevention Through Environmental Design (CPTDE) - Prevenção Criminal Através do Desenho Ambiental, para uma variedade de aplicações em moradias e no ambiente construído (COZENS, 2002).
} 
entradas com diferentes materiais de pavimentação; realizar mudanças na elevação da rua e projeto de paisagismo); vigilância natural (evitar paisagismos que possam criar pontos cegos ou esconderijos; distribuição de usos mistos); e controle de acesso (projetar ruas para desencorajar tráfego de alta velocidade; projetar passeios em locais seguros para os pedestres e usá-los para definir limites). Outra dimensão importante diz respeito à manutenção contínua e eficaz, somada à gestão do espaço urbano (manutenção de áreas comuns, equipamentos de iluminação e áreas de estacionamento, passeios limpos e reparados, linhas de visão aberta, plantações e jardins em boas condições), desestimulando o desuso do espaço (por exemplo, abandono).

Tabela 3 - Índice de gestão de efluentes

\begin{tabular}{|c|c|c|c|c|}
\hline Critérios & & Descrição & $\checkmark$ & Pontos \\
\hline $\begin{array}{l}\text { 1. Plano de gestão } \\
\text { de água de } \\
\text { superfície }\end{array}$ & 1.1 & $\begin{array}{l}\text { Existência de um plano local/regional de gestão de água } \\
\text { de superfície }\end{array}$ & & 10 \\
\hline \multirow[t]{4}{*}{$\begin{array}{l}\text { 2. Infiltração e } \\
\text { percolação }\end{array}$} & 2.1 & $\begin{array}{l}\text { Incentivo à infiltração e percolação, visando diminuir o } \\
\text { escoamento superficial }\end{array}$ & & 5 \\
\hline & 2.2 & $\begin{array}{l}\text { Evidência do uso de técnicas para controle da erosão do } \\
\text { solo e de sua cobertura vegetal }\end{array}$ & & 5 \\
\hline & 2.3 & $\begin{array}{l}\text { Aplicação de sistemas de drenagem sustentável: planos } \\
\text { de infiltração, trincheira de infiltração, valos de } \\
\text { infiltração, dispositivos hidráulicos permeáveis, } \\
\text { pavimentação permeável, implementação de coberturas } \\
\text { verdes }\end{array}$ & & 5 \\
\hline & 2.4 & $\begin{array}{l}\text { Existência de infraestrutura para separação entre águas } \\
\text { pluviais poluídas (zonas de estacionamento) e não } \\
\text { poluídas através de uma rede coletora para pré- } \\
\text { tratamento (hidrocarbonetos) antes de devolvê-las ao } \\
\text { solo: valas de infiltração antes de devolver a água ao } \\
\text { solo }\end{array}$ & & 5 \\
\hline \multirow{3}{*}{$\begin{array}{l}3 . \\
\text { Evapotranspiração }\end{array}$} & 3.1 & Corredores ecológicos e ambientais & & 5 \\
\hline & 3.2 & $\begin{array}{l}\text { Existência de planos de manutenção das áreas verdes e } \\
\text { criação de novas zonas para aumentar a } \\
\text { evapotranspiração e a permeabilidade }\end{array}$ & & 5 \\
\hline & 3.3 & $\begin{array}{l}\text { Implementação de coberturas verdes nas infraestruturas } \\
\text { de apoio dos espaços públicos (quando existentes) }\end{array}$ & & 5 \\
\hline $\begin{array}{l}\text { 4. Reutilização das } \\
\text { águas }\end{array}$ & 4.1 & $\begin{array}{l}\text { Introdução de um sistema de tratamento e reutilização } \\
\text { de águas in situ, ETAR }\end{array}$ & & 10 \\
\hline \multirow[t]{3}{*}{$\begin{array}{l}\text { 5. Medidas } \\
\text { adicionais }\end{array}$} & 5.1 & $\begin{array}{l}\text { Existência de alguma estrutura artificial para } \\
\text { armazenamento temporário de água da chuva }\end{array}$ & & 5 \\
\hline & 5.2 & Tratamento e escoamento da água através de Reedbeds & & 5 \\
\hline & 5.3 & $\begin{array}{l}\text { Implementação de técnicas para o aumento da eficiência } \\
\text { do escoamento, com redução do coeficiente }\end{array}$ & & 5 \\
\hline
\end{tabular}

Fonte: BioRegional (2014), Building Research Establishment Global (2009) e Leadership in Energy and Environmental Design (2009). 
Tabela 4 - Índice de segurança nas ruas

\begin{tabular}{|c|c|c|c|c|}
\hline Critérios & & Descrição & $\checkmark$ & Pontos \\
\hline \multirow{4}{*}{$\begin{array}{l}\text { 1. Controlo } \\
\text { natural de } \\
\text { acesso }\end{array}$} & 1.1 & $\begin{array}{l}\text { Limitar o acesso sem desconectar completamente o local das } \\
\text { áreas adjacentes }\end{array}$ & & 1 \\
\hline & 1.2 & $\begin{array}{l}\text { Projetar ruas que evitem os shorts cuts e o tráfego de alta } \\
\text { velocidade }\end{array}$ & & 1 \\
\hline & 1.3 & $\begin{array}{l}\text { Usar plantas e elementos de design de arquitetura para orientar os } \\
\text { visitantes para entradas desejadas e longe de áreas privadas }\end{array}$ & & 1 \\
\hline & 1.4 & $\begin{array}{l}\text { Projetar passeios em locais seguros para os pedestres e usá-los } \\
\text { para definir limites }\end{array}$ & & 1 \\
\hline \multirow{4}{*}{$\begin{array}{l}\text { 2. Vigilância } \\
\text { natural }\end{array}$} & 2.1 & Evitar paisagismo que possa criar pontos cegos e esconderijos & & 1 \\
\hline & 2.2 & $\begin{array}{l}\text { Localizar espaços verdes abertos e áreas de lazer para que sejam } \\
\text { visíveis a partir das residências próximas as ruas }\end{array}$ & & 1 \\
\hline & 2.3 & $\begin{array}{l}\text { Distribuição de usos mistos, permitindo a vigilância natural das } \\
\text { ruas }\end{array}$ & & 1 \\
\hline & 2.4 & $\begin{array}{l}\text { Usar iluminação na escala do pedestre em áreas de alto tráfego } \\
\text { de peões, com o sentido de ajudar a orientação das pessoas e o } \\
\text { reconhecimento das potenciais ameaças à noite, em prol da } \\
\text { segurança }\end{array}$ & & 1 \\
\hline \multirow{3}{*}{$\begin{array}{l}\text { 3. Reforço } \\
\text { territorial }\end{array}$} & 3.1 & $\begin{array}{l}\text { Projetar lotes, ruas e casas que incentivem a interação entre } \\
\text { vizinhos }\end{array}$ & & 1 \\
\hline & 3.2 & $\begin{array}{l}\text { Acentuar entradas com materiais de pavimentação diferentes, } \\
\text { mudanças na elevação das ruas e projeto paisagístico }\end{array}$ & & 1 \\
\hline & 3.3 & $\begin{array}{l}\text { Definir as linhas de propriedade com postes e cercas, portões e } \\
\text { plantação direcionando o tráfego de pedestres em pontos } \\
\text { desejados de acesso apenas }\end{array}$ & & 1 \\
\hline \multirow{6}{*}{ 4. Manutenção } & 4.1 & $\begin{array}{l}\text { Manter todas as áreas comuns a padrões muito elevados, } \\
\text { incluindo entradas e calçadas }\end{array}$ & & 1 \\
\hline & 4.2 & Manter todos os equipamentos de iluminação & & 1 \\
\hline & 4.3 & Manter todos os passeios limpos e reparados & & 1 \\
\hline & 4.4 & $\begin{array}{l}\text { Manter as linhas de visão abertas. Podar as árvores e arbustos } \\
\text { para permitir o acesso visual a todas as áreas do local }\end{array}$ & & 1 \\
\hline & 4.5 & $\begin{array}{l}\text { Manter áreas de estacionamento com alto padrão, sem buracos } \\
\text { ou lixo }\end{array}$ & & 1 \\
\hline & 4.6 & Manter plantações e terrenos em boas condições & & 1 \\
\hline
\end{tabular}

Fonte: Association of Chief Police Officers Secured by Design (2009) e Office of Disaster Preparedness and Management e Home Office (2004).

\section{Transporte público}

O objetivo deste indicador é promover boas práticas de mobilidade, melhorando a qualidade dos transportes públicos e as conexões locais que estabelecem. O principal objetivo consiste em reduzir o uso do veículo privado. Os transportes públicos foram bastante valorizados nos projetos de regeneração urbana. Uma grande oferta de meios de transportes foi encontrada, assim como grande investimento em infraestrutura, para 
melhorar a qualidade ou criar novos meios de transporte, rotas e acessos.

O desempenho dos projetos de regeneração urbana ao nível deste parâmetro foi avaliado através do índice da qualidade e frequência dos transportes públicos, que consiste no somatório dos pontos correspondentes a cada um dos critérios apresentados na Tabela 5. Adicionalmente, este índice considera que, para os critérios $1,4,5$ e 6 , apenas um subcritério poderá ser escolhido - não podendo haver a soma de pontos entre eles. Existindo mais de uma opção, deverá considerar-se a que resulta em maior pontuação. Para os critérios 2 e 3 poderá existir a soma de pontos dos diversos subcritérios. O somatório máximo é igual a 75 pontos. Após, este resultado deverá ser convertido para porcentagem. A seleção dos critérios a serem avaliados foi extraída dos projetos caso de estudo, com influência dos requisitos que são avaliados nas principais ferramentas de avaliação da sustentabilidade de projetos de planejamento urbano e comunidades. A melhor prática será o projeto de regeneração urbana que registre o índice igual ou superior a $70 \%$.

Tabela 5 - Índice da qualidade e frequência dos transportes públicos

\begin{tabular}{|c|c|c|c|c|}
\hline Critérios & & Descrição & $\checkmark$ & Pontos \\
\hline \multirow{3}{*}{ 1. Estado de conservação } & 1.1 & Bom estado de conservação & & 10 \\
\hline & 1.2 & Razoável estado de conservação & & 5 \\
\hline & 1.3 & Mau estado de conservação & & 0 \\
\hline \multirow{10}{*}{$\begin{array}{l}\text { 2. Tipo de transportes } \\
\text { disponíveis (opções) }\end{array}$} & 2.1 & Micro-ônibus & & 2 \\
\hline & 2.2 & Ônibus & & 2 \\
\hline & 2.3 & BRT (bus rapid transit) & & 2 \\
\hline & 2.4 & Trams (metrô de superfície/elétrico) & & 2 \\
\hline & 2.5 & Metrô subterrâneo & & 2 \\
\hline & 2.6 & Trem (regional/internacional) & & 2 \\
\hline & 2.7 & Trem de alta velocidade (TGV) & & 2 \\
\hline & 2.8 & Transporte fluvial & & 2 \\
\hline & 2.9 & Esquema de bicicletas & & 2 \\
\hline & 2.10 & Esquema de partilha de automóveis & & 2 \\
\hline \multirow{5}{*}{ 3. Infraestruturas } & 3.1 & Pontos de carga para veículos elétricos & & 2 \\
\hline & 3.2 & Vias dedicadas para ônibus/BRT & & 2 \\
\hline & 3.3 & Vias dedicadas para trams & & 2 \\
\hline & 3.4 & Vias partilhadas de trams e autocarros & & 2 \\
\hline & 3.5 & Intercâmbio de transportes & & 2 \\
\hline \multirow{3}{*}{$\begin{array}{l}\text { 4. Frequência dos } \\
\text { transportes - áreas } \\
\text { urbanas }\end{array}$} & 4.1 & Intervalos de passagem a cada $10 \mathrm{~min}$ & & 10 \\
\hline & 4.2 & Intervalos de passagem entre 10 e $15 \mathrm{~min}$ & & 5 \\
\hline & 4.3 & Intervalos de passagem maiores que $15 \mathrm{~min}$ & & 0 \\
\hline \multirow{4}{*}{$\begin{array}{l}\text { 5. Proximidade média das } \\
\text { paragens }\end{array}$} & 5.1 & $<400 \mathrm{~m}$ & & 15 \\
\hline & 5.2 & $400-600 \mathrm{~m}$ & & 10 \\
\hline & 5.3 & $600-1000 \mathrm{~m}$ & & 5 \\
\hline & 5.4 & $>1000 \mathrm{~m}$ & & 0 \\
\hline \multirow{3}{*}{$\begin{array}{l}\text { 6. Paradas dos transportes } \\
\text { públicos }\end{array}$} & 6.1 & Paradas cobertas, protegidas e com banco de apoio & & 10 \\
\hline & 6.2 & Paradas cobertas, protegidas e sem banco de apoio & & 5 \\
\hline & 6.3 & Paradas descobertas & & 0 \\
\hline
\end{tabular}

Fonte: Open House (2014), Comissão de Coordenação e Desenvolvimento Regional do Norte (2010) e Building Research Establishment Global (2009). 


\section{Rede de ciclovias}

O objetivo deste indicador é promover o uso da bicicleta como uma opção viável de transporte (seguro e de qualidade) para deslocamentos entre zonas residenciais, educacionais, comerciais e industriais. Assim, promove-se o uso de meios de transporte nada poluentes, servindo como alternativa ao uso de transportes poluentes. Este indicador foi avaliado através do índice de qualidade da rede de ciclovias (Tabela 6), constituído por uma lista de verificação com fatores variáveis. Tal índice é igual ao somatório dos pontos correspondentes aos critérios apresentados na Tabela 6 , tendo ainda em conta que, para os critérios $1,2,3,4$ e 5 , apenas um subcritério poderá ser escolhido - não podendo haver a soma de pontos entre eles. Existindo mais de uma opção, considera-se a de maior valor. O somatório máximo é igual a 80 pontos. Após, este resultado deverá ser convertido para porcentagem.

Tabela 6 - Índice de qualidade da rede de ciclovias

\begin{tabular}{|c|c|c|c|c|}
\hline Critérios & & Descrição & $\checkmark$ & Pontos \\
\hline \multirow{2}{*}{$\begin{array}{l}\text { 1. Plano de } \\
\text { redes cicláveis }\end{array}$} & 1.1 & Inexistente & & 0 \\
\hline & 1.2 & Plano local ou regional & & 10 \\
\hline \multirow{6}{*}{$\begin{array}{l}\text { 2. Tipo e } \\
\text { segurança de } \\
\text { vias }\end{array}$} & 2.1 & Inexistência de ciclovias & & 0 \\
\hline & 2.2 & $\begin{array}{l}\text { Vias partilhadas (pedestre-ciclovia) de sentido unidirecional, } \\
\text { com largura } \geq 1,5 \mathrm{~m}\end{array}$ & & 10 \\
\hline & 2.3 & $\begin{array}{l}\text { Vias partilhadas (pedestre-ciclovia) de sentido bidirecional, } \\
\text { com largura } \geq 2,5 \mathrm{~m}\end{array}$ & & 15 \\
\hline & 2.4 & $\begin{array}{l}\text { Vias partilhadas (rodovia-ciclovia) unidirecionais, sem } \\
\text { separação física e largura } \geq 1,5 \mathrm{~m}\end{array}$ & & 10 \\
\hline & 2.5 & $\begin{array}{l}\text { Vias partilhadas (rodovia-ciclovia) unidirecionais, com } \\
\text { separação física e largura } \geq 1,5 \mathrm{~m}\end{array}$ & & 15 \\
\hline & 2.6 & $\begin{array}{l}\text { Vias dedicadas segregadas de sentido bidirecional, com largura } \\
\geq 2,5 \mathrm{~m}\end{array}$ & & 15 \\
\hline \multirow{3}{*}{$\begin{array}{l}3 . \\
\text { Estacionamento } \\
\text { de bicicletas }\end{array}$} & 3.1 & Inexistência de estacionamento & & 0 \\
\hline & 3.2 & Descoberto & & 10 \\
\hline & 3.3 & Coberto & & 15 \\
\hline \multirow{5}{*}{$\begin{array}{l}\text { 4. Conexões } \\
\text { com ciclovias } \\
\text { externas à área } \\
\text { de intervenção } \\
\text { (a partir de seu } \\
\text { limite) }\end{array}$} & 4.1 & Distância excede os 1.500 m & & 0 \\
\hline & 4.2 & Distância $>1.000 \mathrm{~m} \mathrm{e} \leq 1.500 \mathrm{~m}$ & & 5 \\
\hline & 4.3 & Distância $>500 \mathrm{~m} \mathrm{e} \leq 1.000 \mathrm{~m}$ & & 10 \\
\hline & 4.4 & Distância $\leq 500$ m & & 15 \\
\hline & 4.5 & $\begin{array}{l}\text { Ciclovia dentro do limite da área de intervenção que estabelece } \\
\text { a ligação entre dois pontos relevantes, prolongando-se a uma } \\
\text { ciclovia externa }\end{array}$ & & 20 \\
\hline \multirow{4}{*}{$\begin{array}{l}\text { 5. Características } \\
\text { das ciclovias }\end{array}$} & 5.1 & Existência de áreas cobertas clicáveis & & 5 \\
\hline & 5.2 & Existência de áreas arborizadas clicáveis & & 5 \\
\hline & 5.3 & Existência de áreas de descanso & & 5 \\
\hline & 5.4 & Existência de estações de aluguel de bicicletas & & 5 \\
\hline
\end{tabular}

Fonte: Futuro Sustentável (2014) e Leadership in Energy and Environmental Design (2009) e Building Research Establishment Global (2009). 
Os três projetos disponibilizaram ciclovias para seus moradores e visitantes. $\mathrm{O}$ projeto $\mathrm{La}$ Confluence, no entanto, destaca-se pela qualidade das ciclovias oferecidas, com um índice de $94 \%$.

Para obter um bom desempenho ao nível deste indicador, o projeto de regeneração urbana deverá, primeiramente, verificar e avaliar a aptidão do terreno para ser frequentado por ciclistas. Estando a zona de intervenção apta à implantação de ciclovia, o projeto deverá conter um plano urbanístico capaz de oferecer condições para uma mobilidade mais saudável, promovendo o desenvolvimento de uma rede de percursos cicláveis de qualidade, contínuos e seguros para os utilizadores. Esta rede deverá estar articulada, preferencialmente, com os diferentes meios de transporte, estar provida de instalações de apoio aos ciclistas e ser, ao mesmo tempo, atrativa. A melhor prática será o projeto de regeneração urbana que apresentar o índice de qualidade da rede de ciclovias com valor igual ou superior a $85 \%$.

\section{Espaços urbanos públicos}

O objetivo deste indicador é promover a identidade e o sentido de comunidade local, através da destinação de espaços urbanos públicos de qualidade. Analisando os projetos, verificou-se que uma grande porcentagem das áreas foi destinada a espaços urbanos públicos, com uma média superior a $43 \%$ da área total do empreendimento. Este indicador permite avaliar o percentual de espaços urbanos públicos de qualidade acessíveis à população no âmbito do projeto de regeneração urbana.

O desempenho dos projetos de regeneração urbana ao nível deste indicador dá-se através da avaliação da porcentagem de espaços urbanos públicos, que resulta do quociente entre o somatório de áreas destinadas a espaços urbanos públicos e o total da área de intervenção.

Tendo por base os resultados obtidos, a melhor prática será o projeto que destine uma área de espaços urbanos públicos de qualidade igual ou superior a $40 \%$ da área total do projeto. A qualidade e a diversidade dos espaços públicos, juntamente com a existência de uma rede de caminhos que conectem os espaços públicos, são aspectos avaliados a partir de uma lista de verificação.

\section{Integração e inclusão social}

O principal objetivo deste indicador é promover habitação acessível a um amplo espectro de pessoas (idade, classe social, religião, etnia, etc.), além de promover a participação da população desde as fases preliminares de projeto. Este indicador é avaliado por dois parâmetros, um quantitativo e um qualitativo. Tanto o Parque Olímpico como La Confluence tiveram grande preocupação em promover a habitação social, destinando boa parte das novas construções a esta tipologia. O projeto do Parque das Nações não destinou uma porcentagem das moradias para habitação social, e a participação da população no projeto foi pequena.

O desempenho dos projetos de regeneração urbana foi avaliado por meio de dois índices: índice de participação da população no processo de regeneração urbana, constituído por uma lista de verificação com fatores variáveis; e índice de habitações destinadas à integração e inclusão social, que resulta do quociente entre o somatório de habitações sociais e residências para jovens previstas e o número total de frações habitacionais previstas.

O valor do índice de participação da população será igual ao somatório dos pontos correspondentes a cada um dos critérios apresentados na Tabela 7, tendo em conta que o somatório máximo é igual a 120 pontos. Após, este resultado deverá ser convertido para porcentagem.

Devido à inexistência de legislação em vigor que determine os índices mínimos para habitação social em projetos de regeneração urbana, serão utilizados como referência os valores dos projetos de regeneração urbana internacionais. Dessa forma, a melhor prática para o índice de habitações destinadas à integração e inclusão social será equivalente a valores iguais ou superiores a $20 \%$. A melhor prática para o índice de participação da população, avaliado por uma lista de verificação, será de valores iguais ou superiores a $75 \%$, o que corresponde a um projeto que promova a participação da população por meio de reuniões, workshops, voluntariado (ONGs); providencie suporte para os negócios locais e empresas; promova um plano estratégico que inclua estudo demostrando o número necessário de habitações sociais; ofereça diferentes tipologias de casas a preços acessíveis (famílias de baixa renda, estudantes, jovens casais e pessoas com deficiência), com tamanhos diferenciados, que não sejam, aparentemente, diferentes das outras residências. 
Tabela 7 - Índice de participação da população

\begin{tabular}{|c|c|c|c|c|}
\hline Critérios & & Descrição & $\checkmark$ & Pontos \\
\hline \multirow{2}{*}{$\begin{array}{l}\text { 1. Participação } \\
\text { da população }\end{array}$} & 1.1 & Inexistente & & 0 \\
\hline & 1.2 & Existente & & 10 \\
\hline \multirow{7}{*}{$\begin{array}{l}\text { 2. Ações } \\
\text { realizadas na } \\
\text { comunidade }\end{array}$} & 2.1 & $\begin{array}{l}\text { Reuniões envolvendo a comunidade local para tomada de } \\
\text { decisões do projeto }\end{array}$ & & 10 \\
\hline & 2.2 & $\begin{array}{l}\text { Desenvolvimento de cursos de capacitação para os } \\
\text { residentes - aquisição de competências e qualificações } \\
\text { técnicas adequadas em diversas áreas }\end{array}$ & & 10 \\
\hline & 2.3 & Suporte para as pequenas e médias empresas locais & & 10 \\
\hline & 2.4 & Existência de serviços de voluntariado, ONGs & & 10 \\
\hline & 2.5 & $\begin{array}{l}\text { Realização de workshops de incentivo aos moradores } \\
\text { para terem atitudes ecorresponsáveis }\end{array}$ & & 10 \\
\hline & 2.6 & $\begin{array}{l}\text { Existência de escritório da entidade responsável pelo } \\
\text { projeto dentro da área de intervenção para atender } \\
\text { profissionais, estudantes, residentes, turistas, etc. }\end{array}$ & & 10 \\
\hline & 2.7 & Existência e distribuição do guia de bairro & & 10 \\
\hline \multirow{2}{*}{$\begin{array}{l}\text { 3. Plano } \\
\text { estratégico }\end{array}$} & 3.1 & Inexistência de plano estratégico & & 0 \\
\hline & 3.2 & $\begin{array}{l}\text { Plano estratégico que contemple estudo demonstrando o } \\
\text { número de habitações sociais necessárias a preços } \\
\text { compatíveis/acessíveis }\end{array}$ & & 10 \\
\hline \multirow[t]{3}{*}{ 4. Tipologias } & 4.1 & $\begin{array}{l}\text { São considerados pelo menos três das diferentes } \\
\text { tipologias de habitação social: famílias de baixa e média } \\
\text { renda, estudantes, casais jovens, idosos, deficientes }\end{array}$ & & 10 \\
\hline & 4.2 & São considerados diferentes tamanhos de moradias & & 10 \\
\hline & 4.3 & $\begin{array}{l}\text { As habitações sociais são indistinguíveis das outras } \\
\text { habitações e integradas no contexto local }\end{array}$ & & 10 \\
\hline & & TOTAL & & \\
\hline
\end{tabular}

Fonte: BioRegional (2014), Leadership in Energy and Environmental Design (2009) e Building Research Establishment Global (2009).

\section{Empregabilidade}

O objetivo deste indicador é promover, através do projeto de regeneração urbana, o crescimento do emprego local e a formação profissional dos residentes. Espera-se que o projeto tenha competência para criar estratégias de promoção do emprego local (temporário e permanente), durantes as fases de construção e operação. Este indicador foi avaliado através do índice de empregabilidade (Tabela 8), que consiste em uma lista de verificação com fatores variáveis. $\mathrm{O}$ valor deste índice será igual ao somatório dos pontos correspondentes a cada um dos critérios apresentados na Tabela 8, tendo em conta que o somatório máximo é igual a 120 pontos. Após, este resultado deverá ser convertido para porcentagem.

O projeto de Londres apresentou melhores resultados, uma vez que um dos principais objetivos era resolver um grande problema identificado na região do Lower Lea Valley: o alto índice de desemprego. O London Employment and Skills Action Plan for 2012 (GREATER..., 2008) promoveu cursos de aprendizagem e uma academia de habilidades para construção dentro da área do Parque Olímpico, que ajudou os londrinos a obter emprego com os empreiteiros locais.

Com base na análise dos projetos, a melhor prática será o projeto de regeneração urbana que apresente índice de empregabilidade igual ou superior a 
75\%. A fim de obter um bom desempenho neste indicador, o projeto de regeneração urbana deve realizar um estudo econômico que abranja aspectos como negócios existentes na área, índices de desemprego, fornecimento de facilidades $\mathrm{e}$ localização dos tipos de negócios. O projeto deve também promover a empregabilidade através da utilização de trabalhadores locais, disponibilização de cursos de formação e promoção do aumento do número de postos de trabalho e da economia local.

Tabela 8 - Índice de empregabilidade

\begin{tabular}{|c|c|c|c|c|}
\hline Critérios & & Descrição & $\checkmark$ & Pontos \\
\hline \multirow{2}{*}{$\begin{array}{l}\text { 1. Estudo } \\
\text { econômico }\end{array}$} & 1.1 & Inexistente & & 0 \\
\hline & 1.2 & $\begin{array}{l}\text { Um estudo econômico (ou relatório de investigação) foi } \\
\text { realizado abordando aspetos relacionados à área de } \\
\text { intervenção: tipos de negócios; taxas de desemprego; } \\
\text { prestação de serviços; localização dos negócios, etc. }\end{array}$ & & 20 \\
\hline \multirow[t]{7}{*}{ 2. Empregabilidade } & 2.1 & $\begin{array}{l}\text { No processo de regeneração urbana, trabalhadores e/ou } \\
\text { empreiteiros locais serão utilizados durante a fase de } \\
\text { construção }\end{array}$ & & 10 \\
\hline & 2.2 & $\begin{array}{l}\text { No processo de regeneração urbana, trabalhadores e/ou } \\
\text { empreiteiros locais serão utilizados durante as fases de } \\
\text { manutenção e operação (pós-construção) }\end{array}$ & & 10 \\
\hline & 2.3 & $\begin{array}{l}\text { Durante o processo de regeneração urbana, cursos de } \\
\text { formação e aperfeiçoamento da mão de obra local foram } \\
\text { disponibilizados, por meio de parcerias com centros de } \\
\text { aprendizagem e formação locais, para ser utilizados durante } \\
\text { a fase de construção ou operação }\end{array}$ & & 10 \\
\hline & 2.4 & $\begin{array}{l}\text { Os formandos foram contratados pela empresa responsável } \\
\text { pelo processo de regeneração urbana ou por outra empresa }\end{array}$ & & 10 \\
\hline & 2.5 & $\begin{array}{l}\text { Os empregos locais são destinados a uma variada gama de } \\
\text { faixas etárias, competências e habilidades técnicas }\end{array}$ & & 10 \\
\hline & 2.6 & $\begin{array}{l}\text { O processo de regeneração urbana não reduzirá o número de } \\
\text { postos de trabalho permanentes dentro da área local }\end{array}$ & & 10 \\
\hline & 2.7 & $\begin{array}{l}\text { Com o processo de regeneração urbana, o número de postos } \\
\text { de trabalho locais aumentará }\end{array}$ & & 10 \\
\hline \multirow[t]{3}{*}{$\begin{array}{l}\text { 3. Economia } \\
\text { local }\end{array}$} & 3.1 & $\begin{array}{l}\text { Durante o processo de regeneração urbana, novos negócios, } \\
\text { bem como pequenas e médias empresas locais tiveram apoio } \\
\text { de entidades formadoras com vistas à profissionalização das } \\
\text { atividades }\end{array}$ & & 10 \\
\hline & 3.2 & $\begin{array}{l}\text { Foram destinados edifícios novos e/ou reabilitados para } \\
\text { novas atividades comerciais/serviços ou atividades de } \\
\text { formação }\end{array}$ & & 10 \\
\hline & 3.3 & $\begin{array}{l}\text { Com o objetivo de promover a economia, emprego e } \\
\text { formação local, o processo de regeneração urbana constituiu } \\
\text { aliança entre particulares, entidades públicas e instituições } \\
\text { de ensino }\end{array}$ & & 10 \\
\hline
\end{tabular}

Fonte: BioRegional (2014), Leadership in Energy and Environmental Design (2009) e Building Research Establishment Global (2009). 


\section{Conclusão}

Tendo em consideração que (i) a sustentabilidade é um conceito lato, que inclui todas as relações entre um projeto e as questões ambientais, sociais e econômicas dele, (ii) o conceito de cidade sustentável não está normalizado, nem é aceito do mesmo modo à escala global, (iii) na generalidade, as cidades atuais não são sustentáveis e (iv) prevêse um grande crescimento das cidades nos próximos anos, em resultado do abandono das zonas rurais, entre outros fatores, torna-se necessário o desenvolvimento de instrumentos adequados que permitam apoiar projetistas e tomadores de decisões no desenvolvimento e na regeneração sustentável das cidades.

O desenvolvimento de casos de estudo é visto como um importante instrumento para a disseminação do conceito "regeneração urbana sustentável" e para a demonstração das mais-valias resultantes da aplicação prática de medidas que resultem em projetos de regeneração urbana mais sustentáveis. Adicionalmente, o desenvolvimento de metodologias que permitam, de uma forma sistematizada, apoiar projetistas no desenvolvimento de projetos mais sustentáveis e possibilitar o reconhecimento dos benefícios associados a esse tipo de projeto são vitais para a materialização desse conceito.

Sob essa perspectiva, este trabalho analisou três projetos europeus de regeneração urbana, com o objetivo de auxiliar a definição de melhores práticas para dez indicadores de sustentabilidade da ferramenta SBTool ${ }^{\mathrm{PT}}$-PU. Os níveis de melhores práticas foram definidos com base na análise dos projetos utilizados como estudo de caso e análise das ferramentas de avaliação da sustentabilidade de projetos de planejamento urbano e comunidades, bem como considerando as melhores estratégias utilizadas na Europa. Um dos principais objetivos da ferramenta $\mathrm{SBTool}^{\mathrm{PT}}$-PU é apoiar os projetistas no desenvolvimento de projetos urbanos mais sustentáveis, uma vez que as melhores práticas representam as metas a serem alcançadas, servindo de incentivo para o desenvolvimento de projetos sustentáveis, bem como para avaliações e comparações entre diferentes projetos, mesmo durante as fases preliminares deles. Assim sendo, de acordo com os contextos português e internacional sobre a sustentabilidade de operações de desenvolvimento urbano, espera-se que a definição das melhores práticas para projetos de regeneração urbana sustentável e a metodologia de avaliação da sustentabilidade apresentada contribuam para um maior entendimento e discussão em escala internacional sobre a temática da cidade sustentável e das principais práticas de projeto e gestão delas, que resultem num ambiente construído com nível de desempenho superior.

\section{Referências}

ASSOCIATION OF CHIEF POLICE OFFICERS SECURITY BY DESIGN. New Homes 2010.

Londres, 2009.

AGÊNCIA PORTUGUESA DO AMBIENTE. Descontaminação do Solo e Áreas Minerais Degradadas. Disponível em: $<$ http://www.apambiente.pt/index.php?ref=16\&sub ref=84\&sub2ref=222>. Acesso em: 01 set. 2014.

BIOREGIONAL. One Planet Living. Disponível em: http://www.bioregional.com/oneplanetliving/. Acesso em: 4 maio de 2014.

BRAGANÇA, L. et al. Approaching Sustainability in Built Environment. In: INTERNATIONAL CONFERENCE ON SUSTAINABLE BUILDING ASIA, Seul, 2013. Proceedings... Seul, 2013.

BUILDING RESEARCH ESTABLISHMENT GLOBAL. BREEAM Communities. SD5065 Technical Guidance Manual. BREEAM for Communities Assessor Manual Development Planning Application Stage. BRE Global Ltd. Inglaterra, 2009.

\section{COMISSÃO DE COORDENAÇÃO E DESENVOLVIMENTO REGIONAL DO NORTE. Manual de Planeamento das} Acessibilidades e da Gestão Viária. Portugal: Comissão de Coordenação e Desenvolvimento Regional do Norte, 2010. Volume 13 - Transportes públicos.

\section{COMPREHENSIVE ASSESSMENT SYSTEM} FOR BUILT ENVIRONMENT EFFICIENCY. CASBEE for Urban Development. Technical manual 2007 Edition. Institute for Building Environment and Energy Conservation. Japão, 2007.

COUCH, C.; SYKES, O.; BÖRSTINGHAUS, W. Thirty Years of Urban Regeneration in Britain, Germany and France: the importance of context and path dependency. Progress in Planning, v. 75, n. 1, p. 1-52, 2011.

COZENS, P. M. Sustainable Urban Development and Crime Prevention Through Environmental Design For the British City: towards an effective urban environmentalism for the 21 st Century. Cities, v. 19, n. 2, p. 129-137, 2002.

DALE, A.; NEWMAN, L. Sustainable Development For Some: green urban development and affordability. Local Environment, v. 14, n. 7, p. 669-681, 2009. 
EARTHCRAFT COMMUNITIES. EarthCraft Communities Guidelines. Atlanta: Southface Energy Institute, 2013.

FULLER, R. A.; GASTON, K. J. The Scaling of Green Space Coverage in European Cities.

Biology Letters, v. 5, n. 3, p. 352-355, 2009.

FUTURO SUSTENTÁVEL. Guia de Boas Práticas Para a Concepção de Ciclovias. Disponível em:

<http://www.futurosustentavel.org/fotos/plano/Pag es_from_Pages_from_plano_mobilidade_FSII_fin al_parteIV_a.pdf>. Acesso em: 3 maio 2014.

GREATER LONDON AUTHORITY. Five Legacy Commitments. Londres: GLA, 2008.

GREEN BUILDING COUNCIL AUSTRALIA.

Green Star Communities. Disponível em: <http://www.gbca.org.au/green-star/green-starcommunities/>. Acesso em: 5 maio 2014.

HAAPIO, A. Towards Sustainable Urban Communities. Environmental Impact Assessment Review, v. 32, n. 1, p. 165-169, 2012.

HAWKES, J. Jason Hawkes Aerial

Photographer. Disponível em: http://www.jasonhawkes.com/. Acesso em: 4 set. 2013.

HEMPHILL, L.; BERRY, J.; MCGREAL, S. An Indicator-Based Approach to Measuring Sustainable Urban Regeneration Performance: part 1, conceptual foundations and methodological framework. Urban Studies, v. 41, n. 4, p. 725755, 2004a.

HEMPHILL, L.; BERRY, J.; MCGREAL, S. An Indicator-Based Approach to Measuring Sustainable Urban Regeneration Performance: part 2, empirical evaluation and case-study analysis. Urban Studies, v. 41, n. 4, p. 757-772, 2004b.

INTERNATIONAL INITIATIVE FOR A SUSTAINABLE BUILT ENVIRONMENT. Working Groups iiSBE. Disponível em: <http://www.iisbe.org/r-n-d>. Acesso em: 11 maio 2014.

LEADERSHIP IN ENERGY AND ENVIRONMENTAL DESIGN. LEED 2009 For Neighborhood Development. Washington: The U.S. Green Building Council, Inc., 2009.

LONDON LEGACY DEVELOPMENT CORPORATION. Your Sustainability Guide to Queen Elizabeth Olympic Park 2030. Londres, 2012.

MATEUS, R.; BRAGANÇA, L. Sustainability Assessment and Rating of Buildings: developing the methodology SBToolPT-H. Building and Environment, v. 46, n. 10, p. 1962-1971, 2011.
MENDES, L. A Regeneração Urbana na Política de Cidades: inflexão entre o fordismo e o pósfordismo. Revista Brasileira de Gestão Urbana, v. 5, n. 1, p. 33-45, 2013.

MIANA, A. C. Adensamento e Forma Urbana: inserção de parâmetros ambientais no processo de projeto. São Paulo, 2010. 393 f. Tese (Doutorado em Arquitetura e Urbanismo) - Faculdade de Arquitetura e Urbanismo da Universidade de São Paulo, São Paulo, 2010.

OFFICE OF DISASTER PREPAREDNESS AND MANAGEMENT; HOME OFFICE. Safer Places: the planning system and crime prevention. Londres: Thomas Telford, 2004.

OLYMPIC PARK LEGACY COMPANY. Creating the Green Elizabeth Olympic Park: post-games transformation. Londres: OPLC, 2012.

OPEN HOUSE. Assessment Guideline.

Disponível em: <http://www.openhousefp7.eu/assets/files/OPEN_HOUSE_AG1.2.pdf>. Acesso em: 2 maio 2014.

PACHECO-TORGAL, F.; JALALI, S. Earth Construction: lessons from the past for future ecoefficient construction. Construction and Building Materials, v. 29, p. 512-519, abr. 2012.

PARQUE EXPO. Projeto Parque das Nações. Disponível em:

<http://www.parqueexpo.pt/conteudo.aspx?caso=p rojeto\&lang $=$ pt\&id_object $=832 \&$ name $=$ Parque das-Nacoes>. Acesso em: 5 maio 2014.

PORTAL DAS NAÇÕES. Planta do Parque das Nações. Disponível em:

$<$ http://www.portaldasnacoes.pt/images/stories/doc umentos/parque_das_nacoes/projecto/planos/Plant a.pdf>. Acesso em: 2 maio 2014.

ROBERTS, P.; SYKES, H. Urban Regeneration: a handbook. Londres: Sage, 2000.

ROSALES, N. Towards the Modeling of Sustainability Into Urban Planning: using indicators to build sustainable cities. Procedia Engineering, v. 21, p. 641-647, jan. 2011.

SALAT, S.; LABBÉ, F.; NOWACKI, C. Cities and Forms: on sustainable urbanism. Paris: Hermann, 2011.

SINGH, V. S.; PANDEY, D. N.; CHAUDHRY, P. Urban Forests and Open Green Spaces: lessons for Jaipur, Rajasthan, India. Índia: Rajasthan State Pollution Control Board, 2010.

SOUZA, C. L.; AWAD, J. M. Cidades

Sustentáveis, Cidades Inteligentes. São Paulo: Bookman, 2012. 


\section{SPLA LYON CONFLUENCE. La Confluence ${ }^{\circledR}$} Lyon - Press file. França, 2012.

TURCU, C. Local Experiences of Urban Sustainability: researching housing market renewal interventions in three English neighbourhoods, Progress in Planning, v. 78, n. 3, p. 101-150, 2012.
UNITED NATIONS. Department of Economic and Social Affairs, Population Division. World Urbanization Prospects: the 2011 revision. New York: U.S., 2012.

\section{Guilherme Silveira Castanheira}

Departamento de Engenharia Civil, Laboratório de Física e Tecnologia das Construções | Universidade do Minho | Alameda da

Universidade, Azurém | Guimarães - Portugal | CEP 4800-058 | Tel.: (51) 8222-4824 | E-mail: guilhermecastanheira@hotmail.com

\section{Luís Bragança}

Departamento de Engenharia Civil, Centro de Investigação em Território, Ambiente e Construção | Universidade do Minho | Tel.: (351) 253-510-241 | E-mail: braganca@civil.uminho.pt

\section{Ricardo Mateus}

Departamento de Engenharia Civil, Centro de Investigação em Território, Ambiente e Construção | Universidade do Minho | Tel.: (351) 253-510-200 | E-mail: ricardomateus@civil.uminho.pt

\section{Revista Ambiente Construído}

Associação Nacional de Tecnologia do Ambiente Construído

Av. Osvaldo Aranha, $99-3^{\circ}$ andar, Centro

Porto Alegre - RS - Brasil

$$
\text { CEP } 90035-190
$$

Telefone: +55 (51) 3308-4084

Fax: +55 (51) 3308-4054

www.seer.ufrgs.br/ambienteconstruido

E-mail: ambienteconstruido@ufrgs.br 